\title{
STATISTICAL ANALYSES FOR SIMULATING SCHEDULE NETWORKS
}

\author{
Dong-Eun Lee \\ Jonathan Jingsheng Shi \\ Construction Engineering and Management Program \\ Department of Civil and Architectural Engineering \\ Illinois Institute of Technology \\ 3201S. Dearborn St., \\ Chicago, IL 60616-3793, U.S.A.
}

\begin{abstract}
This paper introduces the Stochastic Project Scheduling Simulation (SPSS) system and two additional useful statistical analysis tools. SPSS integrates CPM, PERT, and Discrete Event Simulation (DES) scheduling methods into one system. It can generate a CPM-based deterministic schedule, a PERT-based probabilistic schedule, and a simulationbased stochastic schedule for the project under study. Two additional statistical analysis tools are added to assist users in determining the number of simulation runs needed for a given schedule network and testing the significance of difference between two independent simulation experiments.
\end{abstract}

\section{INTRODUCTION}

Due to the limitations of CPM and PERT scheduling methods, simulation has been applied to schedule networks by considering random activity durations for estimating project durations (Douglas 1978, Ahuja and Nandakumar 1985). Moreover, simulation has been widely employed as a useful tool for planning construction processes or operations (Martinez and Ioannou 1997, 1999, Ahuja 1984, Ioannou 1989, Shi 1999, Hajjar and AbouRizk 1999).

A construction project may be consisted of hundreds or thousands of activities. When simulation is applied to schedule a project, the first question must be answered is how many simulation runs must be conducted. Number of simulation runs needed is project-specific. It is jointly affected by many factors such as number of activities in the project, relationships between activities, formulation of the critical path(s), and distributions of activity durations.

A simulation cannot be executed indefinitely. Generally speaking, a large number of simulation runs leads to a statistically valid simulation results but it will consume a long computing time. Although new computing technology has made computing time not a major concern for small to medium projects, computing time may be still crucial for large projects, e.g., with thousands of activities. Reducing un- needed simulation runs will improve the efficiency of a simulation process. The validity of simulation results depends upon the number of simulation runs. If it is terminated prematurely, the obtained results may not objectively represent the process under study and therefore be invalid. Properly determining the number of runs needed for a given project helps determine the minimal computing time and ensure valid results. Moreover, when multiple simulation experiments are conducted for the same schedule network, different results may be obtained due to different streams of random numbers. It is essential to examine the difference between the results of the different experiments. They should be statistically identical in order to valid the experiments.

This article discusses two important statistical factors for schedule simulation: (1) determining number of simulation runs for a given schedule network, and (2) testing the significance of the difference between any two simulation experiments. JAVA components are developed in the SPSS system for carrying out the two functions.

\section{THE STOCHASTIC PROJECT SCHEDULE SIMULATION (SPSS) SYSTEM}

The SPSS system provides a computer tool for analyzing a schedule network by using CPM, PERT, and DES methods (Lee 2004). CPM uses a deterministic approach, PERT uses a probabilistic approach, and DES uses a discrete event simulation approach for scheduling construction projects. Although PERT shows an advantage over CPM by providing a probabilistic approach for representing activity durations, a PERT schedule has found to be conservative because the method systematically underestimates the probability to complete a project in a given time (Halpin and Riggs 1992, Shi 2001). The DES approach would improve the accuracy of a PERT schedule. SPSS allows a user to select any preferred methods freely and to compare the schedules from the three methods for a given project. SPSS can assist a user in estimating the probability of completing a project within a given time. SPSS collects all 
of the results from the conducted simulation runs and conduct statistical analyses accordingly.

\section{THE METHODOLOGY}

Calculating the probability of completing a project in a given time using simulation technique involves: (1) determining the activity durations, (2) conducting a simulation experiment for the network and determining the critical path in the network, (3) computing project duration with the longest path, and (4) conducting multiple simulation runs by repeating steps 1 to 3 , and (5) computing mean project duration, standard deviation, and probability to complete the project in a desired time.

SPSS was implemented with the three scheduling methods (CPM, PERT, and DES) as shown in Figures 1, 2, 3 , respectively (Lee 2004). The same activity diagram is shared by the three methods in SPSS as shown in Figure 4.

If the DES scheduling method is selected, the user may enter a desired number of simulation runs as shown in Figure 3. However, the program will calculate the minimum number of simulation runs needed based on the given confidence level. If the number of simulation runs is given by the user, the system will return a confidence interval for the mean project duration under a given confidence.

Three point estimates (optimistic, most-likely, and pessimistic times) are used in PERT. For comparison pur- pose, the same three point estimates are used for the activities of the schedule network under simulation study. Triangular distributions are used modeling for activity durations (2) in Figure 4).

A simulation experiment will be conducted for 120 runs with simulation results to be collected from each run. Then, the mean project duration and its confidence interval are calculated for the samples in the experiment. Estimating the confidence interval requires the mean $(\mu)$ and standard deviation $(\sigma)$ of the population. Since the population standard deviation is unknown, an unbiased estimate of the standard deviation $\left(\mathrm{S}_{\mathrm{x}}\right)$ is used as the standard deviation of the population $\sigma$ (Mohammadi 2002). If a desired project duration is given, SPSS can also calculate the probability for the project to be completed in the given time as shown in Figure 3.

\subsection{Determining the Number of Simulation Runs}

The methodology for computing the minimal number of simulation runs is based on the error term resulted from the sample. SPSS first calculates the unbiased estimates of mean and the standard deviation values. Then the confidence interval of the mean is computed in the range between the lower bound exact mean (LBEM) and upper bound exact mean (UBEM) (Ang and Tang 1975, Khisty and Mohammadi 2001, Mohammadi 2002).

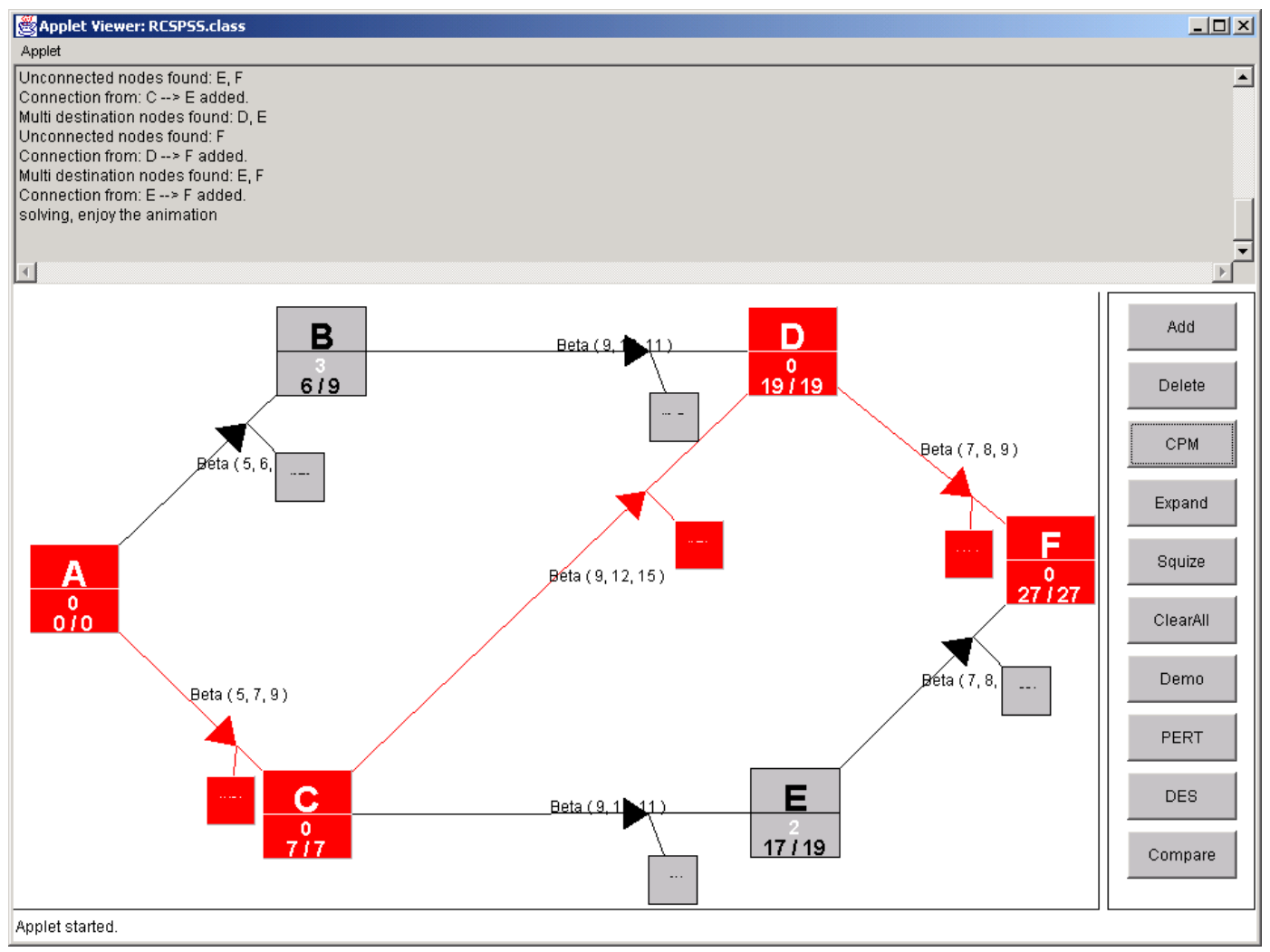

Figure 1: Deterministic CPM in SPSS 


\section{Lee and Shi}

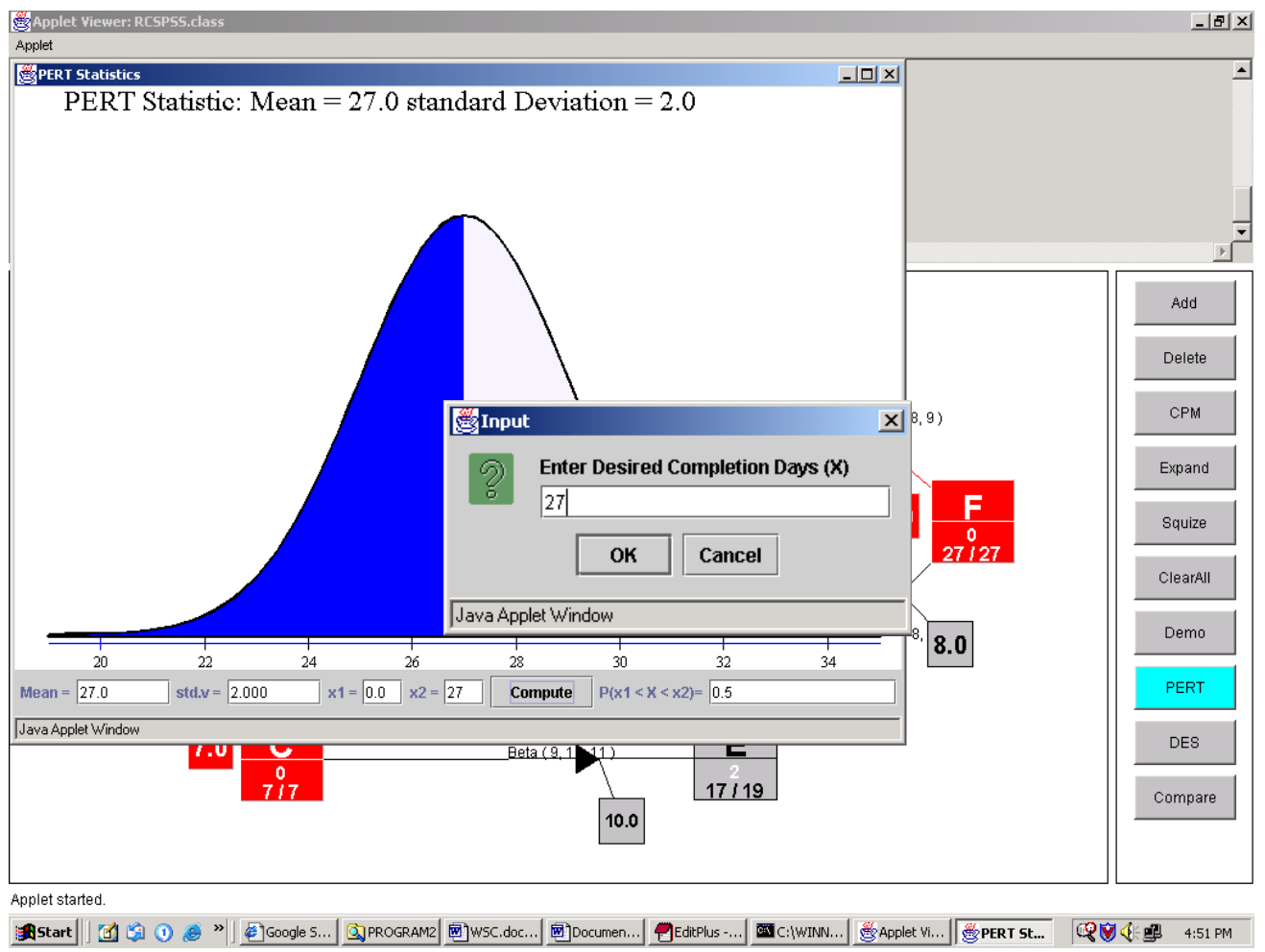

Figure 2: Probabilistic PERT in SPSS

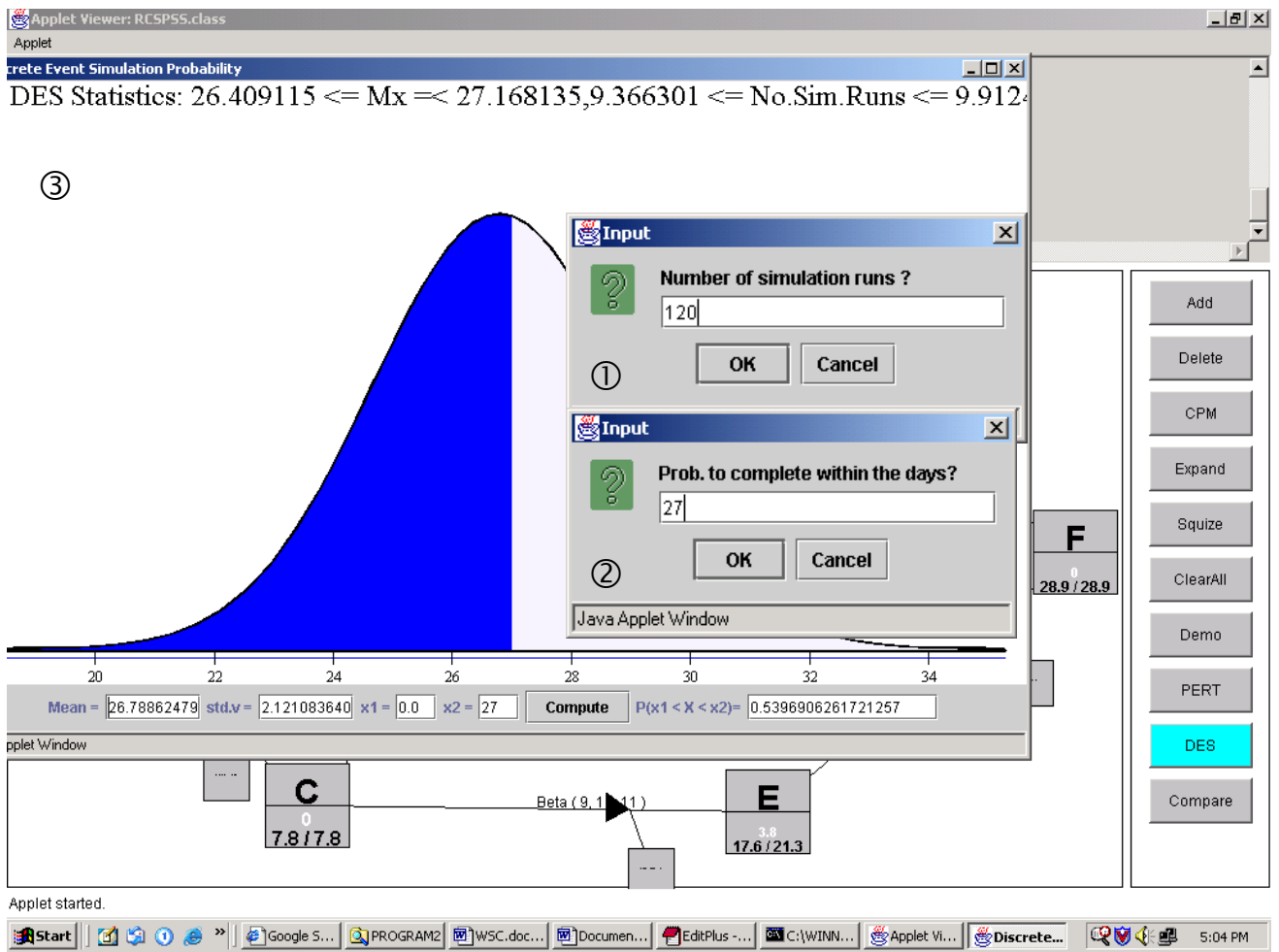

Figure 3: Stochastic Discrete Event Simulation in SPSS 
c: $\operatorname{CPM}(\mathrm{e} 3) / \mathrm{PERT}(\mathrm{o} 3, \mathrm{e} 3, \mathrm{p} 3)$

/Triangular(o3,e3,p3)

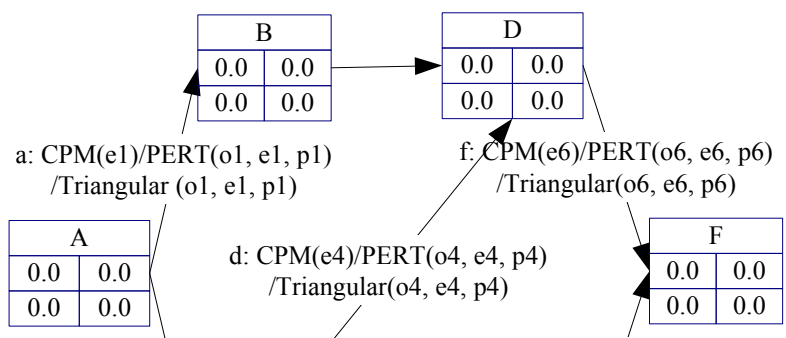

b: $\operatorname{CPM}(\mathrm{e} 2) / \operatorname{PERT}(\mathrm{o} 2, \mathrm{e} 2, \mathrm{p} 2) \quad \mathrm{g}$ : CPM(e7)/PERT(o7, e7, p7)

/Triangular(o2, e2, p2) /Triangular (o7, e7, p7)

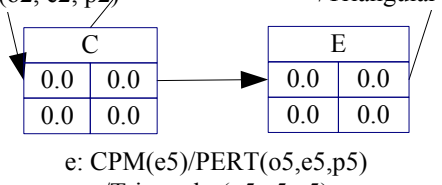

/Triangular(o5,e5,p5)

\begin{tabular}{|c|c|c|c|}
\hline Activity & CPM Mode & PERT Mode & Simulation Mode \\
\hline $\mathrm{a}$ & CPM(e1) & PERT(o1,e1,p1) & Triangular(o1,e1,p1) \\
\hline $\mathrm{b}$ & $\mathrm{CPM}(\mathrm{e} 2)$ & $\operatorname{PERT}(\mathrm{o} 2, \mathrm{e} 2, \mathrm{p} 2)$ & Triangular(o2,e2,p2) \\
\hline $\mathrm{c}$ & CPM(e3) & $\operatorname{PERT}(\mathrm{o} 3, \mathrm{e} 3, \mathrm{p} 3)$ & Triangular(o3,e3,p3) \\
\hline d & CPM(e4) & PERT(o4,e4,p4) & Triangular $(\mathrm{o} 4, \mathrm{e} 4, \mathrm{p} 4)$ \\
\hline e & $\mathrm{CPM}(\mathrm{e} 5)$ & PERT(o5,e5,p5) & Triangular(o5,e5,p5) \\
\hline $\mathrm{f}$ & $\mathrm{CPM}(\mathrm{e} 6)$ & PERT $(06, \mathrm{e} 6, \mathrm{p} 6)$ & Triangular(o6,e6,p6) \\
\hline $\mathrm{g}$ & CPM(e7) & $\operatorname{PERT}(07, \mathrm{e} 7, \mathrm{p} 7)$ & Triangular(o7,e7,p7) \\
\hline \multicolumn{2}{|c|}{$\begin{array}{l}\text { (1) } * \operatorname{PERT}(\mathrm{o}, \mathrm{e}, \mathrm{p}) \\
\text { Double PERT }(\mathrm{o}, \mathrm{e}, \mathrm{p})\{ \\
\text { return }(\mathrm{o}+4 * \mathrm{e}+\mathrm{p}) / 6 \\
\}\end{array}$} & \multicolumn{2}{|c|}{ 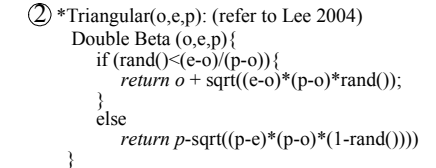 } \\
\hline
\end{tabular}

Figure 4: The Schedule Diagram and Activity Durations

The width of the confidence interval depends on the critical value $\left(t_{\alpha \mid 2}\right)$ and $S_{x}$. A rough estimate of $S_{x}$ could be obtained from the conducted simulation runs. This estimate is used to determine the minimal number of simulation runs $(\mathrm{N})$ (Haas 2004) based on a $95 \%$ confidence level. As shown in Figure 3, the $95 \%$ confidence interval of the mean is in the range of $[26.41,27.19]$ for the given schedule problem with 120 runs. Figure 3 also shows that the minimal number of runs, $\mathrm{N}$ should be in the range $9.37 \leq N \leq 9.91$. As the computation algorithms suggested, the conducted simulation runs (i.e., 120 in this case) are sufficient when N's high range is less than the conducted runs. In other words, it is appropriate to use 120 runs for this project. If the obtained range of $\mathrm{N}$ is greater than the number of conducted simulation runs, extra simulation runs will be conducted.

\subsection{Testing the Significance of the Difference between Two Simulation Experiments}

To test the difference between the mean project duration values of two independent simulation experiments, t-Test is implemented in SPSS. Testing the difference between the variances of two independent simulation runs can also be conducted to check if they are from the same population as shown in Figure 5 by using the F-test. The testing results for the given example are shown in Figure 5.

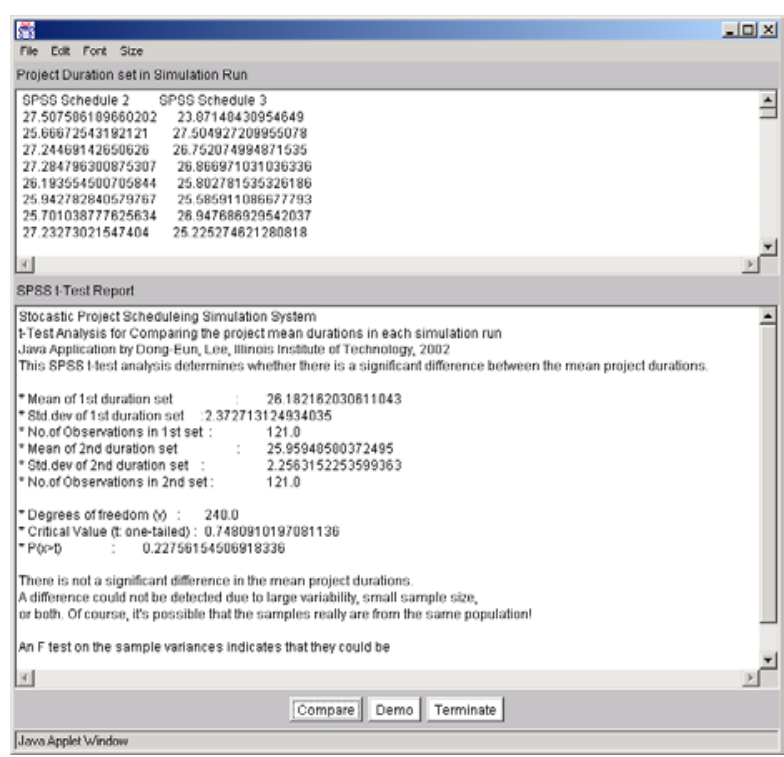

Figure 5: t-Test Results on the Mean Project Duration

\section{A CASE STUDY}

For the given example as shown in Figure 1, the SPSS system calculates (1) a deterministic project duration of 27 days by using the CPM method; (2) a mean project duration of 27 with a standard deviation of 2.0 by using PERT; and (3) and a mean project duration of 26.79 with a standard deviation of 2.12, and a confidence interval ( $26.61 \leq \mu \leq 26.85$ ) for the project duration at the $95 \%$ confidence level.

After eleven (11) independent simulation experiments (each with 120 runs) were conducted, the results are summarized in Figure 6. The mean project durations $\left(\mu_{\text {total }}\right)$ fall in the range $26.08 \leq \mu_{\text {total }} \leq 26.38$ with an overall mean value of 26.22. If one particular experiment is examined, the project durations $(\mu)$ of the 120 runs vary in the range, $23.50 \leq \mu \leq 28.00$ as shown in Figure 7 .

The t-Test shows no significant difference in the mean project durations and F-test on the sample variances indicates that they could be from the same population ( $\alpha$ level of 0.005 ) for the two experiments as shown in Table 1. In conclusion, the two independent simulation experiments are not significantly different. 


\section{Lee and Shi}

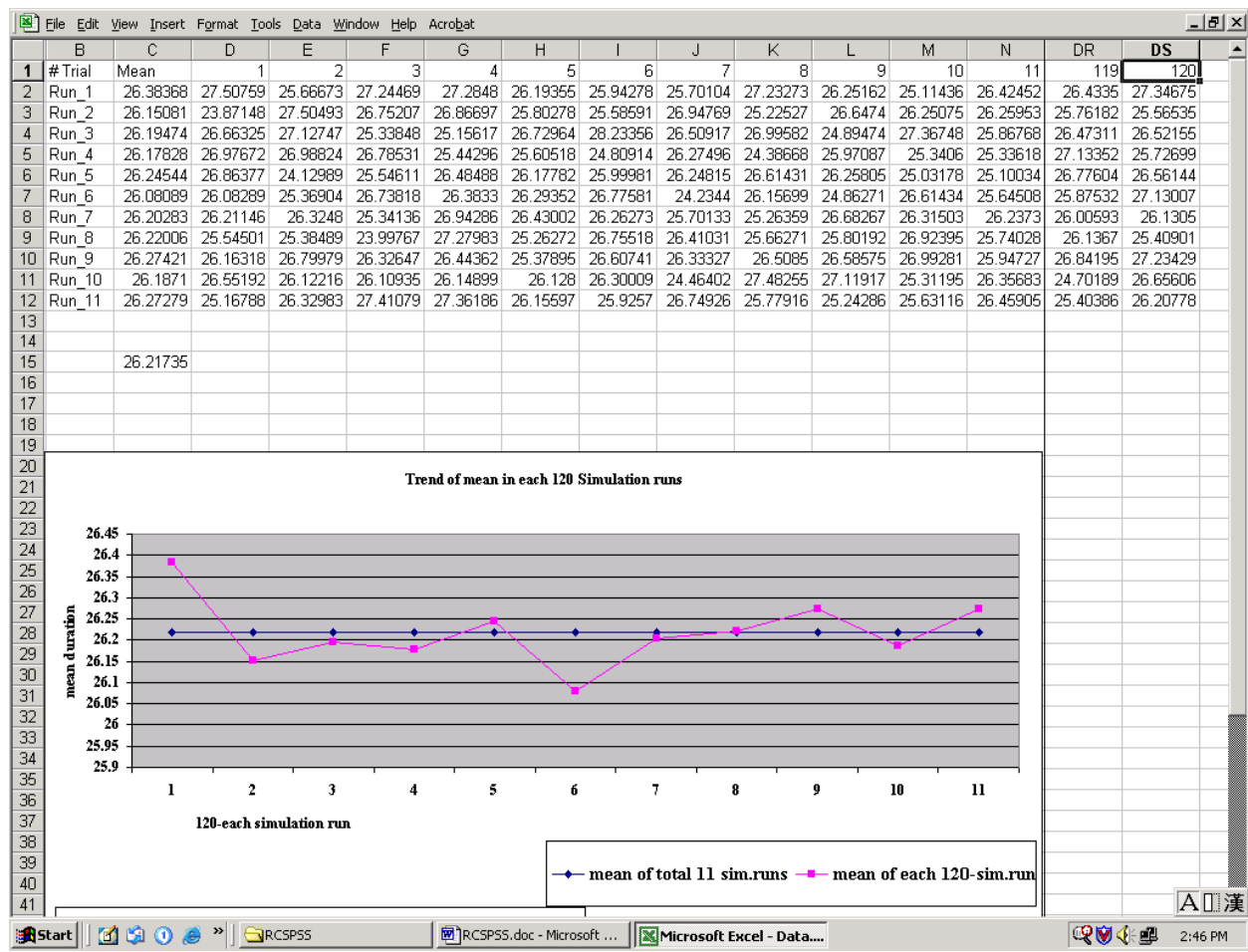

Figure 6: Trend Analysis of Mean Project Durations

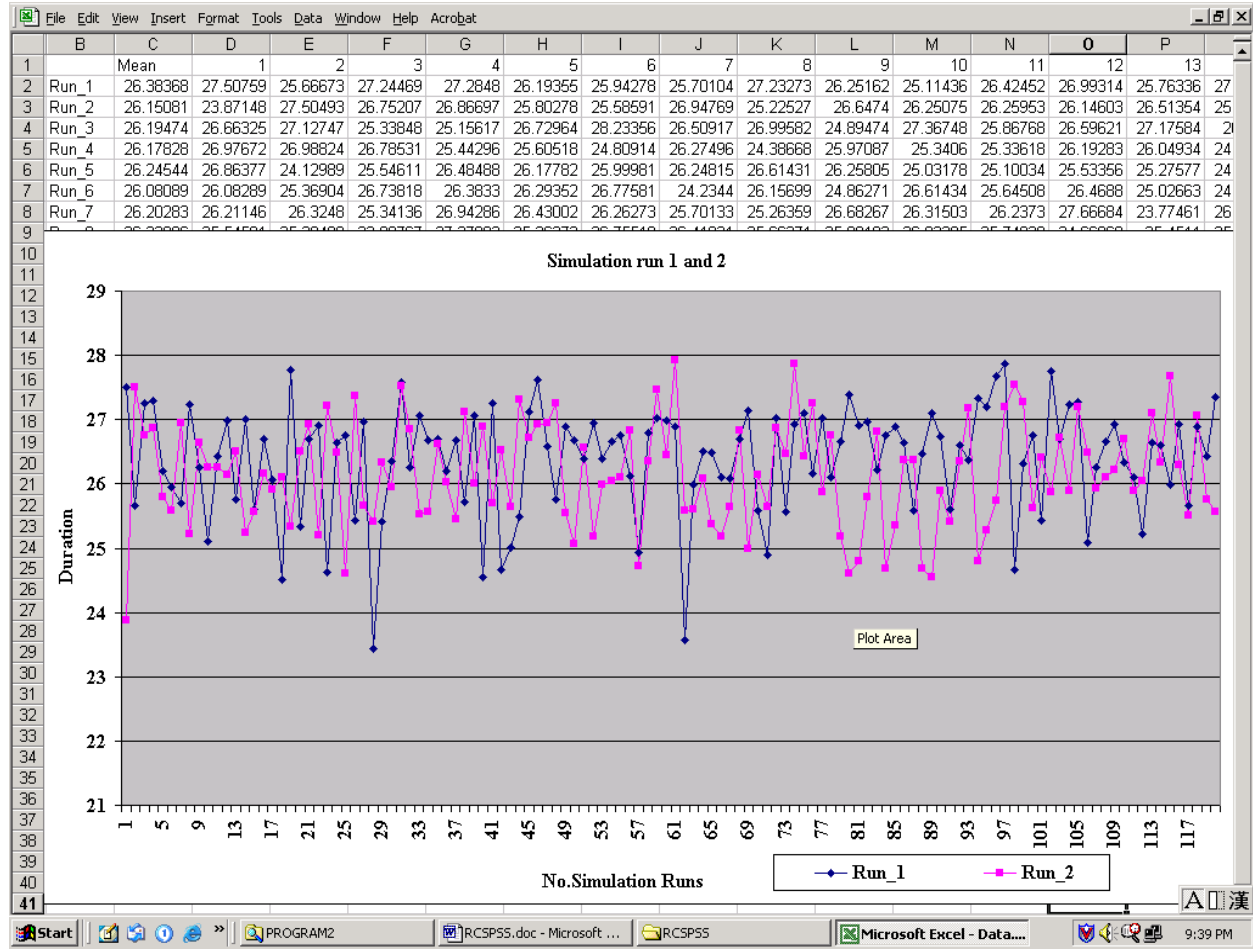

Figure 7: Comparison of Two Different Simulation 
Table 1: t-Test Results on Mean Project Duration

\begin{tabular}{lcc}
\hline \hline & 1st experiment & 2nd experiment \\
\hline Mean & 26.18 & 25.96 \\
Standard deviation & 2.37 & 2.26 \\
No. of Observations & 121 & 121 \\
$\begin{array}{l}\text { Degrees of freedom } \\
\text { (v) }\end{array}$ & 240.0 \\
Critical Value (t: one- & & \\
tailed) & 0.748 \\
P(x>t) & 0.228 \\
Alpha level $(\alpha)$ & 0.005 \\
\hline \hline
\end{tabular}

\section{CONCLUSIONS}

SPSS can support construction scheduling by providing a more accurate prediction of the completion time. The activity data inputted for a project can be shared by the three scheduling methods (CPM, PERT, and DES). The system will provide three different schedules for the project so that the user can compare the differences of these schedules and estimate the potential schedule risks involved in the project.

In summary, the system can (1) forecast the probability of completing a project at a given duration; (2) compare the schedule results from CPM, PERT, and DES methods; (3) determine an appropriate number of simulation runs for a given project, (4) to calculate the probability of completing a project at a given confidence level, and (5) test the significance of difference between two independent simulation experiments.

If the system allows interactive changes of the critical value $\left(\mathrm{t}_{\alpha \mid 2}\right)$ of the $\mathrm{t}$-distribution and the acceptable error term $(\Delta)$, its analytical capability can be enhanced with different confidence values and error terms.

Moreover, more research is required to examine how project durations are effected by skewness and/or variability of activity durations (e.g., high, medium, or low variability). It is also noted that a project duration may become more complicated if there are multiple critical or close-to critical paths in the schedule network. Corresponding t-test methods should be considered.

\section{REFERENCES}

Ahuja, N. Hira. (1984). "Project management: techniques in planning and controlling construction projects." Wiley, New York.

Ahuja, N. T. H., and Nandakumar, V. (1985). "Simulation model to forecast project completion time." Journal of Construction Engineering and Management, ASCE, 111(4), 325-342.

Ang, Alfredo. H-S., and Tang, Wilson. H. (1975). "Probability Concepts in Engineering Planning and Design: Volume I - Basic Principles.” Analytical Models of
Random Phenomena, John Wiley \& Sons, New York. 80-169.

Douglas, E. David. (1978) "PERT and simulation" Proceedings of the 1978 Winter Simulation Conference. Harold J. Highland, IEEE Press, Piscataway, N.J, 89 - 98.

Haas, J. Peter., (2004) "Introduction to Simulation" [online]. Available online via $<$ http://www. stanford. edu/class/msande223/handouts/lecturen otes 01 . pdf> (accessed Apr 20, 2004).

Hajjar, Dany., and AbouRizk, Simaan. M. (1999). "Simphony: An Environment for Building Special Purpose Construction Simulation Tools." Proceedings of the 1999 Winter Simulation Conference. P. A. Farrington, H. B. Nembhard, D. T. Sturrock, and G. W. Evans, eds. IEEE, Piscataway, N.J, 998-1006.

Halpin, D. W. and Riggs L.S. (1992). "Planning and Analysis of Construction Operations." John Wiley \& Sons, New York, N.Y.

Ioannou, P.G. (1989). "UM_CYCLONE User's Guide." Dept. of Civil Engineering, The University of Michigan, Ann Arbor. Mich.

Khisty, C. Jotin., and Mohammadi, Jamshid. (2001). "Fundamental of System Engineering with Economics, Probability, and Statistics." Principles of probability, Prentice Hall. Upper Saddle River, N.J, 131-150, 294 -313 .

Lee, Dong-Eun. (Accepted 2004). "Probability of Project Completion Using Stochastic Project Scheduling Simulation (SPSS)." Journal of Construction Engineering and Management, ASCE.

Martinez, C. Julio., and Ioannou, G. Photios. (1997) "State-Based Probabilistic Scheduling Using STROBOSCOPE's CPM Add-On" Proceedings, Construction Congress V, ASCE, Stuart D. Anderson,ed, Minneapolis, $M N$, 438-445.

Martinez, J.C., and Ioannou, P.G. (1999). "General Purpose Systems for Effective Construction Simulation." Journal of Construction Engineering and Management, ASCE, 125(4), 265-276.

Mohammadi, Jamshid. (2002). "Statistical Analysis of Engineering Data" lecture note in summer 2002. Dept. of Civil Engineering, Illinois Institute of Technology, Chicago, IL.

Shi, J. (1999). "Activity-Based Construction (ABC) Modeling and Simulation Method." Journal of Construction Engineering and Management, ASCE, 125(5), 354-360.

Shi, J. Jonathan. (2001). "Activity-Based Construction (ABC) Modeling and Simulation" Dept. of Civil Engineering, Illinois Institute of Technology, Chicago, IL.

\section{AUTHOR BIOGRAPHIES}

DONG-EUN LEE, P.E., ISO QMS ASSESOR. is a Ph.D. Candidate and Research Assistant in the Construction Engi- 
neering and Management Program in the Department of Civil and Architectural Engineering at Illinois Institute of Technology. Before he joined IIT in 1999, he had worked for Hyosung Group <http : / www . hyosung. com> for 5 years as project engineer and had acted as an registered ISO 9000 Quality Management System Assessor $<$ http: //www.kab.or.kr>. He is a registered Professional Engineer in Korea. He has a B.S. in Civil and Architectural Engineering from Chung-Ang University in Seoul (1993), and a M.S. in Civil Engineering from Illinois Institute of Technology (2000). Lee defended his Ph.D. thesis in Summer 2004. Currently, he is working for the NK Construction Consultant, Inc., New York as a project scheduler. His research interests include construction business process modeling and automation and the development and application of Workflow Management Systems using simulation. His other research interests include construction scheduling and planning method, simulation, and mathematical programming. His e-mail address is <leedong1@ iit. edus.

JONATHAN JINGSHENG SHI, Ph. D., P. E. is an Associate Professor in the Department of Civil and Architectural Engineering at Illinois Institute of Technology in Chicago. He received his Ph.D. in Civil Engineering from the University of Alberta in 1995. His research interests in simulation are focused on automated modeling, simulation, and optimization in construction application. His current researches has been extended to construction automation and innovation as investigating fundamental issues relating to construction enterprise resource planning systems (Construct-ERP) and development of enterprise wide system architecture. His other research interests include neural networks, construction scheduling and planning method, and construction productivity and improvement. He has served as committee member of Construction Research Council and Computing in Construction, ASCE and CMAA. His email and web addresses are <shi@iit.edu> and his web address is <http:// www.it. edu/ jshi>. 